Попова A.B.

\title{
РОССИЯ КАК ИНТЕГРАЛЬНАЯ ЦИВИЛИЗАЦИЯ В ТРУДАХ НЕОЛИБЕРАЛЬНЫХ МЫСЛИТЕЛЕЙ НАЧАЛА ХХ ВЕКА
}

Аннотация: Статья посвящена одной из проблем, поставленной в неолиберальной политико-правовой доктрине России кониа XIX-начала XX вв. В структуре российского неолиберализма принято различать идеалистическое и позитивистское направления, различающиеся между собой по вопросам правопонимания и будущего устройства государства. Автор, анализируя взгляды представителей российского неолиберализма рубежа ХІХХХ вв. по проблеме идентификации России как цчивилизации, приходит к выводу, что Россия, в их представлении, представляла собой особый тип цฺивилизации, основанный на теории «заимствования» черт как западно-европейских, так и восточных циивиизаций.

Review: The article is devoted to one of the problems raised in neo-liberal political-legal doctrine of Russia at late XIX - early XX centuries. The structure of Russian neo-liberalism traditionally has an idealistic and positivistic trends, each of them has their own opinion of legal consciousness and future mechanism of government. The author of the present article analyzes views expressed by the followers of Russian neo-liberalism at the turn of XIX-XX centuries on identification of Russia as a civilization. It has been conclude that Russia was regarded as a special form of civilization that was based on the combination of Western European and Eastern features.

Ключевые слова: Юриспруденция, тип цүивилизации, неолиберализм, славянофиль, западники, месторазвитие, теория заимствования, политико-правовая мыслль, Евразия, либерализм

Keywords: legal studies, type of civilization, neo-liberalism, slavophiles, Westerners, developmental place, theory of borrowing, political-legal thought, Eurasia, liberalism.

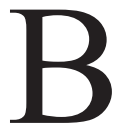
опрос о принадлежности России к отдельному типу цивилизации был поставлен в полемике западников и славянофилов, в рамках которой были сформированы две противоположные точки зрения. Одна - связывала будущее России с ее самоидентификацией в русле западноевропейской традиции, другая - с развитием ее самодостаточности. В конце XIX века полемика славянофилов и западников уступила место дискуссии о месте России между такими направлениями политико-правовой мысли России как либерализм, неолиберализм и консерватизм. «В этой атмосфере переоценки ценностей, роста авторитета позитивного знания философско-исторические изыскания обрели новый статус и стиль: их авторы охотно прибегали к научной (биологической, геополитической, социальной) аргументации, апеллируя к достоверности позитивного знания, а иногда и к естественно-натуралистическим параллелям» ${ }^{1}$. Такие

1 Данилевский Н.Я. Россия и Европа. [Текст] / Н.Я. Данилевский. - Гл. IV, V. - M., 1996. // URL : работы являлись основой для развития неолиберальной концепции заимствования в развитии русской локальной цивилизации.

К наиболее характерным сочинениям такого типа следует отнести работу Н.Я. Данилевского «Россия и Европа», где была предложена новая формула: история есть развитие отдельных культурно-исторических типов, а не единой всемирной цивилизации. История человечества представляет собой развитие локальных культурно-исторических типов, носителем которого является народ. Н.Я. Данилевский наиболее перспективным считал противостоящий западной культуре «славянский тип» цивилизации, полнее всего выраженный в русском народе. По его мнению, каждый культурный тип представлял собой своеобразную «историческую монаду», т.е. самостоятельную, независимую и «непроницаемую» (для других культур) единицу. Человечество может развиваться только «разноместно» и «раз-

http://monarhiya.narod.ru/DNY/dny-list.htm (дата обращения 16.08.2012.). 
новременно», актуализируя различные стороны своего культурно-деятельностного существования. Н.Я. Данилевским было выделено четыре типа такой деятельности: религиозная, собственно культурная (наука, промышленность, искусство), политическая и социально-экономическая. В случае их соединения достигается «провиденциальная цель» истории, поскольку этот синтез и обеспечивает прохождение «исторического поля во всех направлениях», только внутри отдельного культурного типа возможно установление этапов, возможна периодизация истории.

Последователем Н.Я. Данилевского, его теории культурно-исторических типов, придавшим ей новое направление, был К.Н. Леонтьев, который разработал концепцию принадлежности России к восточно-христианскому (византийскому) типу цивилизации. Таким образом, К.Н. Леонтьева в первую очередь занимала проблема стадиальности развития культур, законы их развития и гибели. «Три стадии естественного и культурноисторического развития, обозначенные К. Леонтьевым, связывают два различных динамических процесса: зарождение, развитие, расцвет и - увядание, разложение, смерть» ${ }^{2}$. В основе развития государства лежит развитие культуры, определяя его подъем, расцвет и омертвение. Либерализм неизбежно, по его мнению, должен привести к социализму. «Коммунизм в своих буйных стремлениях к идеалу неподвижного равновесия должен рядом различных сочетаний с другими началами привести постепенно, с одной стороны, к меньшей подвижности капитала и собственности, с другой - к новому юридическому неравенству, к новым привилегиям, к стеснениям личной свободы и принудительным корпоративным группам, законам резко очерченным; вероятно, даже к новым формам личного рабства или закрепощения». Призвание России, согласно учению К.Н. Леонтьева, состоит в том, чтобы на основе византизма найти такой образ жизни, который поможет сохранить ей свою самобытность и тем самым будет способствовать ее дальнейшему развитию, но во взаимосвязи с судьбой Европы.

2 Леонтьев К.Н. Византизм и славянство. [Текст] / К.Н. Леонтьев. // Леонтьев Константин. Избранное. - М. : Издательство АCT, 2007. // URL : http: perspektivy.info >print. php?ID=35874 (дата обращения 15.02.2013).
В трудах неолиберальных мыслителей конца XIX - начала XX вв. Россия представляла собой особый тип локальной цивилизации, с одной стороны, находившийся в единой цепи западноевропейских цивилизаций, a, с другой стороны, имевшей свои социокультурные особенности. П.Н. Милюков, утверждал, что общей для славянофилов и западников являлась идея закономерности общественного и государственного развития, но западники искали «эту закономерность не в сведению национального процесса к абсолютному единству, а в объяснении его в конкретном разнообразии» ${ }^{3}$. Неолиберальный мыслитель, полагая, что Россия развивается по-другому, чем Западная Европа, в то же время считал, что нигде, ни в каком общественном строе форма государства не может считаться неизменной - она всегда меняется, как только меняется состав общества или влияние переходит от одного класса к другому. Поэтому при сохранении самобытности развития России, утверждал П.Н. Милюков, существуют необходимые предпосылки ее «вхождения»в один ряд с европейскими государствами ${ }^{4}$.

Другой представитель неолиберализма, П.Б. Струве считал, что Россия не может быть исключением из практики мировой истории, поэтому он предлагал признать российскую «некультурность» и необходимость пойти «на выучку к капитализму». При этом П.Б. Струве был далек от апологетики последнего «как образа жизни» и от мысли рассматривать его в качестве «вечной» формации. Его мировоззрение как неолиберала прошло путь от марксиста к либералу, а затем к синтезу либеральных, религиозно-метафизических и социалистических идей. Общество, по его мнению, постепенно, естественным путем должно продвигаться по пути социального прогресса путем эволюции от крепостного состояния к капитализму, а затем к социалистическому обществу. Поэтому для России ближайшим будущим является не социализм, а капитализм, основным противоречием которого был разрыв между правом и капиталом. М.И. Туган-Барановский разделял отношение П.Б. Струве к марксизму, однако, по его мнению, главным проти-

\footnotetext{
${ }^{3}$ Милюков П.Н. Источники русской истории и русская историография. [Текст] / П.Н. Милюков // Энциклопедический словарь. - Т. XXVIII. - СПб., 1899. - С. 440. ${ }^{4}$ См. подробнее: Попова А.В. Неолиберализм в России. [Текст] / А.В. Попова. - М. : ГУЗ, 2005. - 122 с.
} 


\section{Политика и общество 10 (106) • 2013}

воречием которого было различие между капиталом и этическими началами в обществе. Разработку общественной теории развития он связывал с критическим преодолением и Канта и Маркса, рассматривая кантианство и марксизм как уже пройденные этапы философской мысли. «Нашим лозунгом, - писал он, - должно стать вперед, к созданию новой теории социализма» 5 . Такой теорией он считал «этический социализм». Одновременно с П.Б. Струве и М.И. Туган-Барановским от марксизма отошли Н.А. Бердяев, С.Н. Булгаков, С.Л. Франк и другие «легальные марксисты». Своеобразным манифестом «коллективного» преодоления марксизма стал сборник статей под ред. П.И. Новгородцева «Проблемы идеализма» ${ }^{6}$, в котором в числе других авторов выступили С.Н. Булгаков, П.Б. Струве, Н.А. Бердяев, составившие вскоре вместе с С.Л. Франком ядро нового религиозно-метафизического течения идеалистического направления российского неолиберализма, соединившего идеализм с либерализмом.

К данному течению относился и В.С. Соловьев полагавший, что каждый народ имеет собственное предназначение в истории развития мировой цивилизации, который проходит в своем развитии две стадии. Первая (до человека) может быть определена как естественная эволюция. Вторая - осуществляемая через свободную и сознательную деятельность человека - представляет собственно исторический процесс, идеальной целью которого является восстановление всеединства человека в мире и мира с Богом путем построения Царства Божия на земле. Идеал такого общества В.С. Соловьев видел в свободной теократии, при которой нравственная власть принадлежит Церкви и ее первосвященнику, сила - царю, как персонифицированному выразителю государственности, а право живого совета с Богом - пророкам, «обладателям ключей будущего». Царство Божие для своего действительного явления в этой жизни требует совершеннейшей общественной организации, которая и выраба-

\footnotetext{
${ }^{5}$ Туган-Барановский М.И. Кант и Маркс (по поводу русского перевода сборника статьей Форлендера о Канте и Марксе) [Текст] / М.И. Туган-Барановский. // М.И. Туган-Барановский. К лучшему будущему.- М.: РОССПЭН. 1996. // URL : http://library.by (дата обращения 12.08.2012).

6 Проблемы идеализма Сборник статей. / Под ред. П.И. Новгородцева. [Текст] - М. : Издание Московского Психологического Общества, 1902. - С. 23.
}

тывается всемирной историей. Нормальным обществом В.С. Соловьев считал то, в котором все сферы общественной жизни, сохраняя свою относительную самостоятельность, взаимно дополняют друг друга как составные части одного органического существа, необходимые друг для друга так, что их положительные действия взаимно усиливают, а отрицательные нейтрализуют друг друга. Оптимальным вариантом такого взаимодействия в современном ему российском обществе он считал взаимодействие церкви, государства и земства; церковь при этом обеспечивает нравственное, государство - политическое, а земство - экономическое руководство обществом. Субъектом исторического процесса, согласно Соловьеву, является все человечество, или Богочеловечество, как действительный, хотя и собирательный организм, отдельные части которого - племена, народы, - будучи подчинены целому и им обусловлены, выполняют каждый свою особую, заложенную в них миссию, или идею, которая и реализуется через определенную силу. В истории, писал он, всегда действуют совместно три силы, олицетворяемые в трех типах культуры: мусульманской, западно-европейской и восточно-европейской, или славянской. Первые две борются между собой, приводя мир в «дурную бесконечность, в никуда». Поэтому в истории действует «третья сила» - русский народ, который дает положительное содержание двум первым, освобождает от их односторонности, примиряет единство высшего начала со свободной множественностью частных форм и элементов. По мнению В.С. Соловьева, через органический синтез этих трех сил и реализуется сокровенный смысл истории. Дальнейший прогресс истории зависит от того, писал мыслитель, сможет ли Россия понять и осуществить свое призвание «тихим и умным деланием» ${ }^{7}$.

Тезис об исключительной роли России во всемирной истории получил свое развитие в русской эмиграции в 20-х гг. XX века, когда появилось течение евразийства. Представители этого течения полагали, что Евразия это «месторазвитие» России, во многом определившая ее историю, на-

7 Соловьев В.С. Оправдание добра (Нравственная философия). [Текст] / В.С. Соловьев - T. 1 // URL : http://lib.rus.ec (дата обращения 17.09.2012.). 
циональный характер русского народа. Четыре идеи легли в основу нового учения: 1) утверждение особых путей развития России как Евразии; 2) идея культуры как симфонической личности; 3 ) обоснование идеалов на началах православной веры; 4) учение об идеократическом государстве. Основой евразийства был постулат о том, что России и населяющим ее народам предопределено особое место в человеческой истории, предначертан особый исторический путь и своя миссия. «Россия представляет собой особый мир. Судьбы этого мира в основном, важнейшем протекают отдельно от судьбы стран к Западу от нее (Европа), а также к югу и востоку от нее (Азия). Особый мир этот должно называть Евразией. Народы и люди, проживающие в пределах этого мира, способны к достижению такой степени взаимного понимания и таких форм братского сожительства, которые трудно достижимы для них в отношении народов Европы и Азии» ${ }^{8}$.

Краеугольным камнем евразийства является учение о государстве. Его разработка наряду с Л.П. Карсавиным принадлежит специалисту в области философии и права Н.Н. Алексееву. Евразийская культура выдвигает идею - «государство нового типа», реализующее единство и цельность всех сфер нецерковного евразийского мира. В этом смысле государство стремится стать церковью, т.е. Градом Божиим. Для достижения этой цели оно вынуждено превращать мирскую свободу - произвол в сферу принуждения. Сфера государства есть сфера силы и принуждения. Более того, евразийцы уверены, что чем здоровее культура и народ, тем большей властностью характеризуется его государство. Для того чтобы успешно решать возложенные на него задачи, государство должно обладать не просто сильной властью, но властью, сохраняющей в то же время связь с народом и представляющей его идеалы. В учении евразийцев ее субъектом является «демотический правящий слой», формируемый путем «отбора» из народа, связанный с ним одной идеологией (мировоззрением) и потому способный выражать его подлинные интересы. Демотическая власть принципиально отличается от европейской демократии, основанной на формальном

\footnotetext{
${ }^{8}$ Россия между Европой и Азией: евразийский соблазн.
} [Текст] - М. : Наука, 1993. - С. 217-218. большинстве голосов, поданных за того или другого представителя власти, связь которой с народом в большинстве случаев на этом и заканчивается. Государство, основанное на «демотическом правящем слое», вышедшем из народа и связанном с ним одной идеологией, определялось как идеократическое. Выдвинутый из недр народа правящий слой для выполнения властных функций неизбежно должен противопоставить себя народным массам, которые имеют склонность к стихийным и деструктивным действиям. Выполнение этой функции требует от правящего слоя безоговорочной координации усилий. На это и направлен особый тип «отбора», внутренним законом жизни которого является жесткое подчинение дисциплине и сохранение «чистоты рядов» на основе преданности общему мировоззрению, возведенного в ранг абсолюта и потому не допускающего критики и инакомыслия.

Современные исследователи, обращаясь к идентификации России как цивилизации, также как и сто лет назад, отмечают ее особое положение 9 . Так, А.С. Ахиезер, различая два типа цивилизаций: традиционную (включает все древние государства, средневековую Европу) и либеральную (развитые капиталистические станы), полагает, что Россия застряла между ними, и представляет собой особую промежуточную цивилизацию, сочетающую элементы социальных отношений и культуры обеих цивилизаций. Россия, считает А.С. Ахиезер, в своем историческом развитии вышла за рамки традиционной цивилизации, встала на путь массового, хотя и примитивного, утилитаризма. Но, тем не менее, не сумела преодолеть границу либеральной цивилизации ${ }^{10}$.

На современном этапе, в XXI веке снова встает вопрос о определении России как цивилизации. Президент Российской Федерации В.В. Путин

\footnotetext{
9 Например: Виктор Шаповалов. Российская цивилизация. [Электронный ресурс] // URL : http://www.filgrad.ru/texts3/ shapovalov3.htm (дата обращения 15.08.2012.); Лубский A.B. Россия как цивилизация. [Электронный ресурс] // URL https://sites.google.com/site/civilizacium/home/civilizacium/ rossijskaa-civilizacia (дата обращения 15.08.2012) и т.д.

${ }^{10}$ См. подробнее: Ахиезер А.С., Ильин В.В. Российская цивилизация: содержание, границы, возможности. Теоретическая политология: мир России и Россия в мире. [Текст] / А.С. Ахиезер, В.В. Ильин. - М. : Издательство МГУ, 2000. - 300 с.
} 


\section{Политика и общество 10 (106) • 2013}

поставил перед обществом вопрос о необходимости поиска общенациональной идеи. Данная проблема, на наш взгляд, не может быть адекватно решена без обращения к истории вопроса определения роли России в истории человечества, к вопросу об отношении нашей страны к уже известным в истории цивилизациям и, прежде всего, западной и восточной. Именно поэтому особое значение приобретает обращение в научной мысли конца XIX - начала XX вв., когда Россия находилась, так же как и сейчас, на особом этапе своего развития - осознания своей цивилизационной принадлежности. Россия - это самостоятельный тип цивилизации, основой которой является духовно-нравственные ценности русского народа при четко выраженных поликонфессиональности и полиэтничности. Подобные черты явились следствием исторических условий становления российской государственности как результат «заимствования» западной и восточной типов цивилизации.

\section{Библиография:}

1. Ахиезер А.С., Ильин В.В. Российская цивилизация: содержание, границы, возможности. Теоретическая политология: мир России и Россия в мире. [Текст] / А.С. Ахиезер, В.В. Ильин. - М. : Издательство МГУ, 2000. -300 c.

2. Виктор Шаповалов Российская цивилизация. [Электронный ресурс] // URL : http://www. filgrad.ru/texts3/shapovalov3.htm (дата обращения 15.08.2012.); Лубский А.В. Россия как цивилизация. [Электронный ресурс] // URL : https://sites.google.com/site/civilizacium/ home/civilizacium/rossijskaa-civilizacia (дата обращения 15.08.2012) и т.д.

3. Данилевский Н.Я. Россия и Европа. [Текст] / H.Я. Данилевский. - Гл. IV, V. - M., 1996. // URL : http://monarhiya.narod.ru/DNY/dny-list. htm (дата обращения 16.08.2012.).

4. Леонтьев К.Н. Византизм и славянство. [Текст] / К.Н. Леонтьев. // Леонтьев Константин. Избранное. - М. : Издательство АСТ, 2007. // URL : http: perspektivy.info>print. php?ID=35874 (дата обращения 15.02.2013).

5. Милюков П.Н. Источники русской истории и русская историография. [Текст] / П.Н. Милюков // Энциклопедический словарь. - Т. XXVIII. - СПб., 1899. - С. 440.

6. Попова А.В. Неолиберализм в России. [Текст] / А.В. Попова. - М. : ГУЗ, 2005. - 122 с.

7. Проблемы идеализма Сборник статей. / Под ред. П.И. Новгородцева. [Текст] - М. : Издание Московского Психологического Общества, 1902. - С. 23.

8. Россия между Европой и Азией: евразийский соблазн. [Текст] - М. : Наука, 1993. С. $217-218$.

9. Соловьев В.С. Оправдание добра (Нравственная философия). [Текст] / В.С. Соловьев - T. 1 // URL : http://lib.rus.ec (дата обращения 17.09.2012.).

10. Туган-Барановский М.И. Кант и Маркс (по поводу русского перевода сборника статьей Форлендера о Канте и Марксе) [Текст] / М.И. Туган-Барановский. // М.И. Туган-Барановский. К лучшему будущему.- М.: РОССПЭН. 1996. // URL : http://library.by (дата обращения 12.08.2012).

\section{References (transliteration):}

1. Akhiezer A.C., Il'in V.V. Rossiiskaya tsivilizatsiya: soderzhanie, granitsy, vozmozhnosti. Teoreticheskaya politologiya: mir Rossii i Rossiya v mire. [Tekst] / A.S. Akhiezer, V.V. Il'in. - M. : Izdatel'stvo MGU, 2000. - 300 s.

2. Viktor Shapovalov Rossiiskaya tsivilizatsiya. [Elektronnyi resurs] // URL : http://www.filgrad.ru/texts3/shapovalov3.htm (data obrashcheniya 15.08.2012.); Lubskii A.V. Rossiya kak tsivilizatsiya. [Elektronnyi resurs] // URL : https://sites.google.com/site/civilizacium/ home/civilizacium/rossijskaa-civilizacia (data obrashcheniya 15.08.2012) i t.d.

3. Danilevskii N.Ya. Rossiya i Evropa. [Tekst] / N.Ya. Danilevskii. - Gl. IV, V. - M., 1996. // URL : http://monarhiya.narod.ru/DNY/dny-list. htm (data obrashcheniya 16.08.2012.).

4. Leont'ev K.N. Vizantizm i slavyanstvo. [Tekst] / K.N. Leont'ev. // Leont'ev Konstantin. Izbrannoe. - M. : Izdatel'stvo AST, 2007. // URL : http: perspektivy.info >print.php?ID $=35874$ (data obrashcheniya 15.02.2013). 
5. Milyukov P.N. Istochniki russkoi istorii i russkaya istoriografiya. [Tekst] / P.N. Milyukov // Entsiklopedicheskii slovar'. - T. XXVIII. SPb., 1899. - S. 440.

6. Popova A.V. Neoliberalizm v Rossii. [Tekst]/ A.V. Popova. - M. : GUZ, 2005. - 122 s.

7. Solov'ev V.S. Opravdanie dobra (Nravstvennaya filosofiya). [Tekst] / V.S. Solov'ev -
T. 1 // URL : http://lib.rus.ec (data obrashcheniya 17.09.2012.).

8. Tugan-Baranovskii M.I. Kant i Marks (po povodu russkogo perevoda sbornika stat'ei Forlendera o Kante i Markse) [Tekst] / M.I. Tugan-Baranovskii. // M.I. Tugan-Baranovskii. K luchshemu budushchemu.- M.: ROSSPEN. 1996. // URL : http://library.by (data obrashcheniya 12.08.2012). 